\title{
Fever and hypothermia represent two populations of sepsis patients and are associated with outside temperature
}

\author{
Daniel O. Thomas-Rüddel ${ }^{1,2^{*}}$ (D, Peter Hoffmann ${ }^{3}$, Daniel Schwarzkopf ${ }^{1,2}$, Christian Scheer $^{4}$, Friedhelm Bach ${ }^{5}$, \\ Marcus Komann², Herwig Gerlach ${ }^{6}$, Manfred Weiss ${ }^{7}$, Matthias Lindner ${ }^{8}$, Hendrik Rüddel ${ }^{1,2}$, Philipp Simon 9 , \\ Sven-Olaf Kuhn ${ }^{4}$, Reinhard Wetzker ${ }^{2}$, Michael Bauer ${ }^{1,2}$, Konrad Reinhart ${ }^{1,10}$ and Frank Bloos ${ }^{1,2}$ on behalf of the \\ MEDUSA study group
}

\begin{abstract}
Background: Fever and hypothermia have been observed in septic patients. Their influence on prognosis is subject to ongoing debates.

Methods: We did a secondary analysis of a large clinical dataset from a quality improvement trial. A binary logistic regression model was calculated to assess the association of the thermal response with outcome and a multinomial regression model to assess factors associated with fever or hypothermia.

Results: With 6542 analyzable cases we observed a bimodal temperature response characterized by fever or hypothermia, normothermia was rare. Hypothermia and high fever were both associated with higher lactate values. Hypothermia was associated with higher mortality, but this association was reduced after adjustment for other risk factors. Age, community-acquired sepsis, lower BMI and lower outside temperatures were associated with hypothermia while bacteremia and higher procalcitonin values were associated with high fever.

Conclusions: Septic patients show either a hypothermic or a fever response. Whether hypothermia is a maladaptive response, as indicated by the higher mortality in hypothermic patients, or an adaptive response in patients with limited metabolic reserves under colder environmental conditions, remains an open question.

Trial registration The original trial whose dataset was analyzed was registered at ClinicalTrials.gov (NCT01187134) on August 23, 2010, the first patient was included on July 1, 2011.
\end{abstract}

Keywords: Fever, Sepsis, Outcome, Mortality, Body temperature, PCT, Lactate, Blood cultures, Prognosis

\section{Background}

The great Canadian physician Sir William Osler wrote: "Humanity has but three great enemies: Fever, famine and war; of these by far the greatest, by far the most terrible, is fever." [1]. Fever is caused by release of pyrogens such

*Correspondence: Daniel.thomas@med.uni-jena.de

${ }^{1}$ Center for Sepsis Control and Care, Jena University Hospital, Jena, Germany

Full list of author information is available at the end of the article as acute phase proteins and is frequently the first symptom of infection [2]. Therefore, the terms fever and infection are often used almost synonymously. But it has long been recognized that there are variable thermoregulatory responses in sepsis [3-5]. The sepsis-1 definition of the Systemic Inflammatory Response Syndrome, therefore, had included both fever and hypothermia [6]. The impact of the thermoregulatory response on prognosis is a longlasting debate reaching back to the 1960s, but data are inconclusive. Hypothermia or fever was associated with original author(s) and the source, provide a link to the Creative Commons licence, and indicate if changes were made. The images or other third party material in this article are included in the article's Creative Commons licence, unless indicated otherwise in a credit line to the material. If material is not included in the article's Creative Commons licence and your intended use is not permitted by statutory regulation or exceeds the permitted use, you will need to obtain permission directly from the copyright holder. To view a copy of this licence, visit http://creativecommons.org/licenses/by/4.0/. The Creative Commons Public Domain Dedication waiver (http://creativeco mmons.org/publicdomain/zero/1.0/) applies to the data made available in this article, unless otherwise stated in a credit line to the data. 
protective or detrimental effects in animal models of severe infection or inflammation [7-10]. In a meta-analysis of clinical data, hypothermic sepsis patients showed a higher mortality than those with fever [11]. However, most included studies were small and there was a high heterogeneity.

The immunological theory of resistance versus tolerance as two distinct, well-regulated response patterns to infection gained acceptance over the last decade [12, 13]. Recent animal studies added a pathophysiological and metabolic perspective whereby hypothermia is aimed at tolerance and energy conservation and fever is aimed at pathogen clearance. Physiological fitness, feeding, environmental temperature and the degree of the immune challenge seem to be important factors promoting fever or hypothermia in animal experiments $[10,14,15]$.

To evaluate whether similar processes might play a role in humans, we assessed the thermoregulatory response of septic patients and its association with predisposing factors including environmental temperature, disease severity and outcome in a secondary analysis of a large dataset [16].

\section{Methods \\ Study design}

This is a secondary analysis of the prospectively collected patient-level dataset from the MEDUSA-study-a cluster randomized quality improvement trial aiming to improve early sepsis diagnosis and treatment in the participating hospitals by a multifaceted educational program [16]. The original trial was registered at ClinicalTrials.gov (NCT01187134) and was approved by the local ethics committees (see Additional file 1 for a complete list) at each participating institution and by the responsible data protection boards.

\section{Study population}

Patients treated between July 1, 2011, and May 31, 2015, on the participating intensive care units (ICUs) with proven or suspected infection and at least one new infection-related organ dysfunction were eligible for inclusion. Patients were excluded if they had relevant limitations of therapy, were not treated on a participating ICU or had infection control measures started at another hospital. Characteristics of participating hospitals have been described previously $[16,17]$. As we performed a secondary analysis, no sample size was calculated.

\section{Data collection}

Data collection and definitions were as previously described [16, 17]. Briefly, the onset of severe sepsis or septic shock was defined as the time of first infectionrelated organ dysfunction. Body temperature measurements were taken as part of routine care. A central temperature was measured rectal, tympanic or in the blood stream. For oral, axillary or groin measurements, study personnel was instructed to add $0.5^{\circ} \mathrm{C}$ to approximate a central measurement. The most pathological temperature within the first $24 \mathrm{~h}$ after sepsis onset was recorded once for each patient. Highest values of laboratory parameters but not changes over time were recorded as baseline data within the first $24 \mathrm{~h}$ after the onset of severe sepsis as baseline data.

For the analysis of environmental weather conditions, we used data from the meteorological stations network of the German Meteorological Service (DWD). Daily data from 273 long-term operating weather stations since 1961 to date were selected and interpolated to a regular $12 \times 12 \mathrm{~km}$ grid using an inverse distance weighting (IDW) with a height correction for temperature values [18], resulting in a homogeneous database that is annually expanded and also used for various applications for climate change diagnostic and monitoring on the national level [19]. Mean outside air temperature of the two days before and the day of sepsis onset were matched to cases based on postal codes of the treating hospitals, and the mean for the three days was used for all further analyses.

\section{Data analysis}

Patients were grouped into four groups, i.e., hypothermia $\left(\leq 35.5{ }^{\circ} \mathrm{C}\right)$, normothermia $\left(35.6-37.5{ }^{\circ} \mathrm{C}\right.$ based on published data [20]), mild fever $\left(37.6-38.9{ }^{\circ} \mathrm{C}\right)$ and high fever $\left(\geq 39{ }^{\circ} \mathrm{C}\right)$. Differences between these groups regarding patients' demographic and clinical characteristics were presented by descriptive statistics and assessed by appropriate univariate tests depending on the structure and distribution of data. To investigate the relationship between body temperature and lactate, procalcitonin and mortality, as well as between body temperature and outside temperature graphical representations were used. For a more detailed description of the association to smaller temperature, groups were formed by using $1{ }^{\circ} \mathrm{C}$ intervals within the previously defined groups. As mild fever encompassed a $1.5{ }^{\circ} \mathrm{C}$ interval, it was not further divided. To better visualize the effect of extremely high fever, we used an additional cutoff at $40.5{ }^{\circ} \mathrm{C}$. The nonlinearity of the relations was additionally investigated by using regression analyses with fractional polynomials and plotting the regression predictions [21]. One outlier in body temperature with a temperature of $<25{ }^{\circ} \mathrm{C}$ and four outliers in outside temperature with a temperature of $<-15{ }^{\circ} \mathrm{C}$ were excluded for these. To further identify predictors associated with the four body temperature groups, a multinomial logistic regression model including patient characteristics (age, sex, BMI), infection characteristics (origin and focus of infection, pathogen in blood 
culture), inflammatory markers (procalcitonin, WBC, leucopenia) and mean outside temperature was calculated. Predictors not significantly associated with body temperature were omitted from the final model. To achieve normal distribution for regression analysis, PCT was logarithmically transformed to the base of 10 . To assess whether body temperature and mortality are independently associated, a logistic regression model predicting 28 -day mortality by body temperature intervals was calculated, including patient characteristics (age, sex, BMI), infection characteristics (origin and focus of infection, pathogen in blood culture), inflammatory markers (procalcitonin, WBC, leucopenia), disease severity (SOFA score, lactate, septic shock), time to antibiotics and mean outside temperature as possibly confounding variables. Regression analyses were conducted by generalized hierarchical linear models with a random intercept to adjust for clustering of cases in hospitals. No sensitivity analyses were performed.

A p-value of less or equal to 0.05 was considered statistically significant for all tests. Estimated values are presented with 95\% confidence intervals (CIs). Missing values were handled by pairwise deletion. Analyses were performed using IBM SPSS Statistics 25 (IBM, Armonk, NY), R (Version 3.4.0; R Core Team, Wien, Austria), SAS 9.4 (SAS, Cary, NC) and GraphPad Prism 9 (GraphPad Software, San Diego, CA).

\section{Results}

\section{Patient characteristics}

During the study period, 6561 patients with severe sepsis including septic shock from 40 hospitals were documented. Body temperature was not recorded in 19 patients resulting in 6542 analyzable cases. Body temperatures showed a bimodal distribution pattern with a frequency peak at about $35.5{ }^{\circ} \mathrm{C}$ and an approximately twice times bigger peak between 38 and $38.5{ }^{\circ} \mathrm{C}$ (Fig. 1). Baseline and outcome clinical information depending on body temperature groups are shown in Table 1. Higher lactate levels were observed at both extremes of the body temperature spectrum (Fig. 2A, Additional file 2: aFigure 1), while higher procalcitonin levels were associated with increasingly higher fever (Fig. 2B) and very low body temperatures (Additional file 2: aFigure 2).

\section{Average outside temperature}

Mean local outside temperature before and at sepsis onset was significantly associated with body temperature $(p<0.001$, see Additional file 2: aFigure $3 \& 4)$. With low outside temperatures there was more hypothermia; with high outside temperature there were less hypothermia and more high fever (Fig. 3). Mean outside temperature was not associated with mortality (see Additional file 2: aTable2).

\section{Predictors of hypothermia, normothermia and fever}

A multinomial logistic regression model identified predictors independently associated with the described temperature groups (Table 2). Community-acquired sepsis, an abdominal focus of infection, a lower BMI, higher age and lower outside temperatures were independently associated with hypothermia. A pathogen in blood culture, community or ICU-acquired sepsis and high procalcitonin values were associated with high fever.

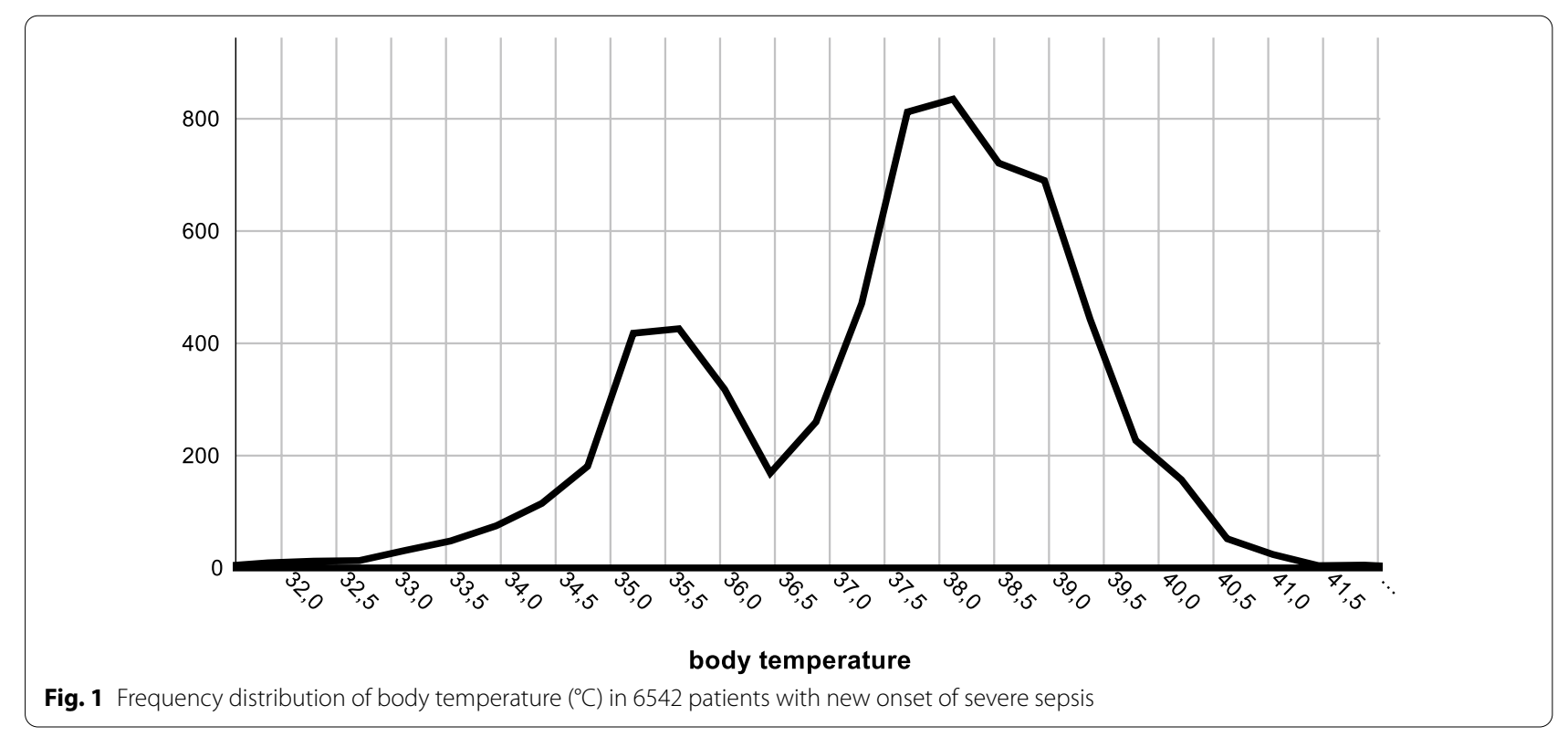


Table 1 Patient characteristics depending on body temperature groups

\begin{tabular}{|c|c|c|c|c|c|c|}
\hline Characteristics & $\begin{array}{l}\text { All patients } \\
(n=6542)\end{array}$ & $\begin{array}{l}\text { Hypothermia } \\
\leq 35.5^{\circ} \mathrm{C} \\
(n=1042)\end{array}$ & $\begin{array}{l}\text { Normothermia } \\
35.6-37.5^{\circ} \mathrm{C} \\
(n=1692)\end{array}$ & $\begin{array}{l}\text { Mild fever } \\
37.6-39^{\circ} \mathrm{C} \\
(n=2550)\end{array}$ & $\begin{array}{l}\text { High fever } \\
\geq 39.1^{\circ} \mathrm{C} \\
(n=1258)\end{array}$ & $p$ value \\
\hline Age (years) & 70 [59-77] & 72 [60-78] & $77[61-79]$ & $70[58-76]$ & $67[55-75]$ & $<0.001$ \\
\hline Sex (male) & $4079(62.4)$ & $606(58.2)$ & $1004(59.3)$ & $1635(64.1)$ & $834(66.3)$ & $<0.001$ \\
\hline Body mass index & $26.3[23.4-30.3]$ & $25,5[22.5-29.2]$ & $26.0[23.0-29.8]$ & $26.6[23.9-30.5]$ & $27,4[1-34]$ & $<0.001$ \\
\hline Origin of infection & & & & & & $<0.001$ \\
\hline Community-acquired & $2790(42.6)$ & $496(47.6)$ & $746(44.1)$ & $976(38.3)$ & $572(45.5)$ & \\
\hline Nosocomial (ICU) & $1471(22.5)$ & $139(13.3)$ & $315(18.6)$ & $678(26.6)$ & $339(26.9)$ & \\
\hline Nosocomial (ward) & $2112(32.3)$ & $367(35.2)$ & $593(35.0)$ & $835(32.7)$ & $317(25.2)$ & \\
\hline Nosocomial (nursing home) & $168(2.6)$ & $39(3.7)$ & $38(2.2)$ & $61(2.4)$ & $30(2.4)$ & \\
\hline \multicolumn{7}{|l|}{ Focus of infection } \\
\hline Respiratory & $2678(40.9)$ & $352(33.8)$ & $593(35.0)$ & $1172(46.0)$ & $561(44.6)$ & $<0.001$ \\
\hline Abdominal & $2422(37.0)$ & $473(45.4)$ & $756(44.7)$ & $896(35.1)$ & $297(23.6)$ & $<0.001$ \\
\hline Urogenital & $869(13.3)$ & $125(12.0)$ & $221(13.1)$ & $288(11.3)$ & $235(18.7)$ & $<0.001$ \\
\hline Bones/soft tissue & $851(13.0)$ & $156(15.0)$ & $249(14.7)$ & $306(12.0)$ & $140(11.1)$ & 0.003 \\
\hline Other & $728(11.1)$ & $97(9.3)$ & $130(7.7)$ & $265(10.4)$ & $236(18.8)$ & $<0.001$ \\
\hline \multicolumn{7}{|l|}{ Clinical data } \\
\hline Pathogen in $B C$ & $2167(40.6)$ & $315(37.5)$ & $458(36.2)$ & $788(38.2)$ & $606(51.6)$ & $<0.001$ \\
\hline РCT (ng/ml) & $5.9[1.6-23.9]$ & $5.4[1.6-21.1]$ & $5.6[1.6-20.7]$ & $5.0[1.3-19.5]$ & $10.6[2.2-39.2]$ & $<0.001$ \\
\hline CRP $(\mathrm{mg} / \mathrm{ml})$ & $204[115-298]$ & 165 [94-263] & 213 [119-304] & 218 [125-307] & 199 [108-288] & $<0.001$ \\
\hline WBC (Gpt/l) & 16.0 [10.5-22.9] & 16.8 [10.9-24.5] & 16.6 [11.4-23.8] & 15.7 [10.3-21.9] & 15.2 [9.6-22.4] & $<0.001$ \\
\hline Leukopenia $($ WBC $\leq 4)$ & $703(10.8)$ & $119(11.4)$ & $159(9.4)$ & $264(10.4)$ & $161(12.8)$ & 0.02 \\
\hline Lactate $(\mathrm{mmol} / \mathrm{l})$ & $2.6[1.6-4.8]$ & $3.8[1.9-8.4]$ & $2.5[1.6-4.5]$ & $2.4[1.5-4.2]$ & $2.5[1.5-4.4]$ & $<0.001$ \\
\hline Urine output (ml/24 h) & 1380 [640-2360] & 920 [260-1840] & $1240[550-2130]$ & 1510 [800-2480] & 1710 [850-2640] & $<0.001$ \\
\hline Heart rate $(-1 / \mathrm{min})$ & 119 [100-135] & 116 [100-134] & 113 [96-130] & 119 [101-134] & 124 [110-140] & $<0.001$ \\
\hline SOFA & $9[6-11]$ & $10[7-12]$ & $8[6-11]$ & $8[6-11]$ & $9[6-11]$ & $<0.001$ \\
\hline Septic shock (Sepsis-3 criteria) & $3513(53,7)$ & $973(66,7)$ & $938(48,7)$ & $967(50,9)$ & $635(50,5)$ & $<0.001$ \\
\hline \multicolumn{7}{|l|}{ Quality of care } \\
\hline Blood cultures drawn & $5342(81.7)$ & $840(80.6)$ & $1266(74.8)$ & $2061(80.8)$ & $1175(93.4)$ & $<0.001$ \\
\hline Time to antibiotics (min) & 98 [15-305] & 115 [20-305] & 103 [10-350] & $105[15-320]$ & $80[15-240]$ & 0.02 \\
\hline \multicolumn{7}{|l|}{ Outcome } \\
\hline New onset dialysis & $1502(23.0)$ & $368(35.3)$ & $374(22.1)$ & $538(19.7)$ & $222(20.7)$ & $<0.001$ \\
\hline ICU mortality & $1952(29.9)$ & $444(42.7)$ & $528(31.3)$ & $677(26.6)$ & $303(24.1)$ & $<0.001$ \\
\hline 28-Day mortality & $2024(31.8)$ & $467(45.7)$ & $539(32.6)$ & $693(28.0)$ & $325(26.6)$ & $<0.001$ \\
\hline Hospital mortality & 2448 (37.5) & $546(52.5)$ & $676(40.0)$ & 850 (33.4) & $376(30.0)$ & $<0.001$ \\
\hline
\end{tabular}

Data are expressed as median [Q1-Q3] or number and percentage, $n(\%) ; p$ values for comparison between body temperature groups by Chi-square or Kruskal-Wallis test

$B C$ blood culture, $P C T$ procalcitonin, $C R P C$-reactive protein, WBC white blood cell count, SOFA Sequential Organ Failure Assessment Score

\section{Mortality}

28-Day mortality was highest (45.7\%) in hypothermic patients and lowest $(27.1 \%)$ in patients with high fever $(p<0.001)$ (Table 1, see Additional file 2: aFigure 5). Looking at smaller body temperature intervals, a decreased mortality could be seen with higher body temperature; for fever $>40.5{ }^{\circ} \mathrm{C}$ there might be a trend toward an increased mortality but without any statistical significance (Fig. 4, see Additional file 2: aTable 2, aFigures 6\&7). After adjustment for baseline variables and disease severity, the increased mortality risk associated with hypothermia was less pronounced while there was no relevant change in the mortality risk for patients with fever (Fig. 4, see Additional file 2: aTables 1\&2). Repeating the analysis with the four body temperature categories showed similar results (Additional file 2: aTables 3\&4).

\section{Discussion}

Using a large dataset, we observed a bimodal distribution of body temperature in septic patients. We could confirm an increased mortality associated with hypothermia that 

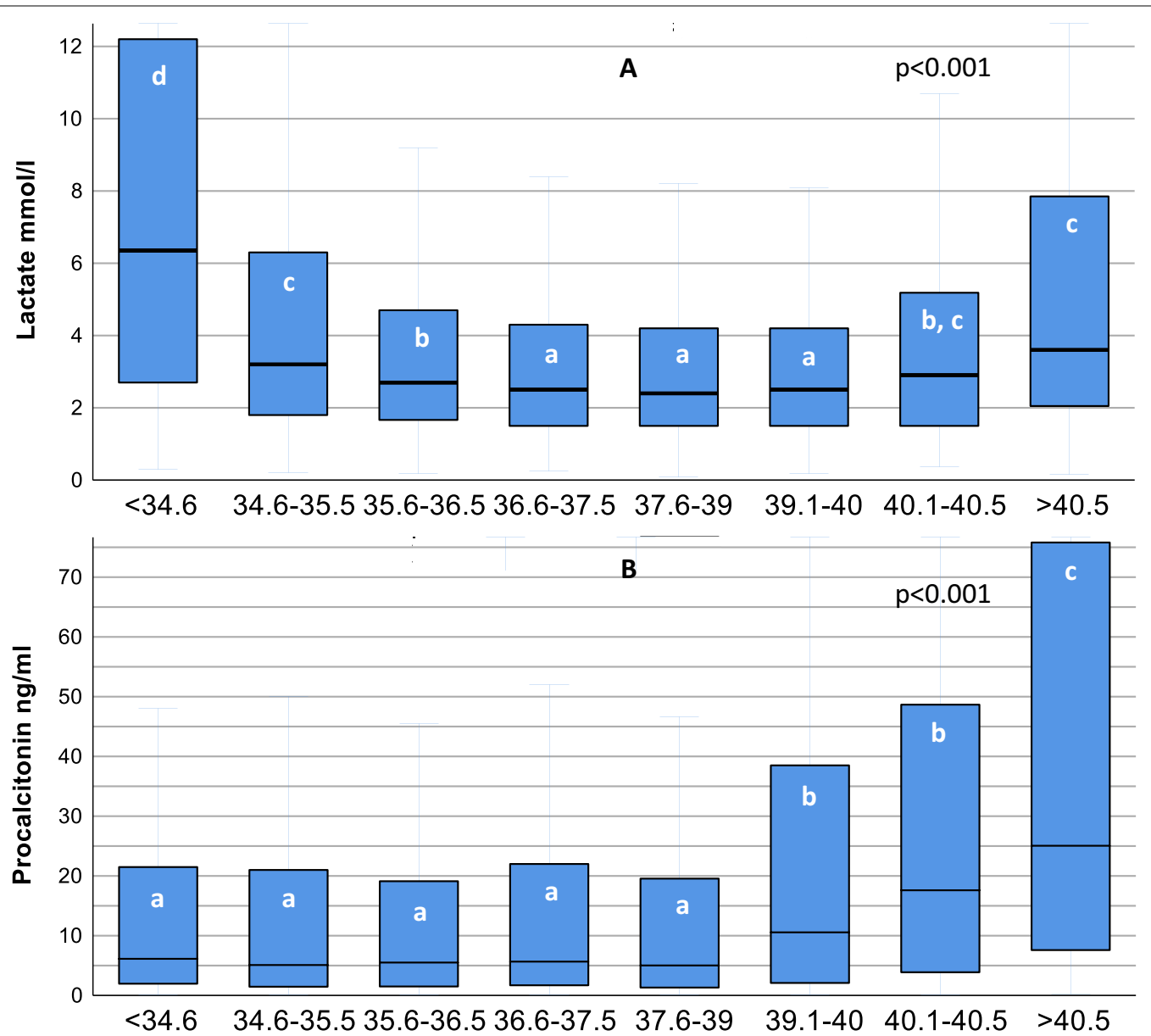

Fig. 2 Lactate concentrations $(\mathrm{mmol} / \mathrm{ml}, \mathbf{a})$ and procalcitonin concentrations $(\mathrm{ng} / \mathrm{ml}, \mathbf{b})$, median and interquartile range, associated with body temperature intervals $\left({ }^{\circ} \mathrm{C}\right) ; p$ value for overall difference, each white letter denotes a homogenous subgroup with increasing values from a to $d$, categories not sharing a common letter are significantly different from each other. Kruskal-Wallis test with stepwise post hoc comparison

was less pronounced after adjustment for disease severity. Community-acquired sepsis, age, lower BMI and an abdominal focus of infection were associated with hypothermia, while bacteremia and a high procalcitonin level were associated with higher fever. Environmental temperature has an influence on body temperature reaction in human sepsis patients.

The definition of normothermia seems to be mostly dependent on age and site of measurement [20]. Our interval of $35.6-37.5{ }^{\circ} \mathrm{C}$ was chosen based on the elderly patients in our dataset, clinical judgment and the advantage of using $0.5^{\circ} \mathrm{C}$ intervals for analysis and readability. The second frequency peak around $35.5^{\circ} \mathrm{C}$ observed in our data is around the lower limit of normal, but those values would be rare in a healthy population. The mean body temperature in such a population would be slightly above $36.5^{\circ} \mathrm{C}$ [20], a value around an observed frequency nadir in our dataset. The obvious interpretation is that severely septic patients show either a hypothermic or more frequently a fever response. The presentation of a portion of septic patients with hypothermia is common knowledge and has been part of the SIRS definition [6], but to our knowledge the bimodal pattern of hyper- or hypothermic response where normothermic patients are a rarity has not been described that clearly before.

Fever is a physiological and strongly preserved reaction to infection slowing the growth of bacteria, stopping the growth of most fungi and enhancing bacterial killing by immune cells $[2,22,23]$. Pathogens in blood culture and higher procalcitonin levels, both associated with high fever in our data, might represent a degree of pathogen challenge where a strong immune resistance is most beneficial. Previous studies have shown conflicting results regarding an association of circulating TNF- $\alpha$ or several interleukins with the type of thermoregulatory response in septic patients [24-27]. But procalcitonin kinetics might be better suited to measure inflammatory activation than TNF- $\alpha$ or interleukins whose peak values are 


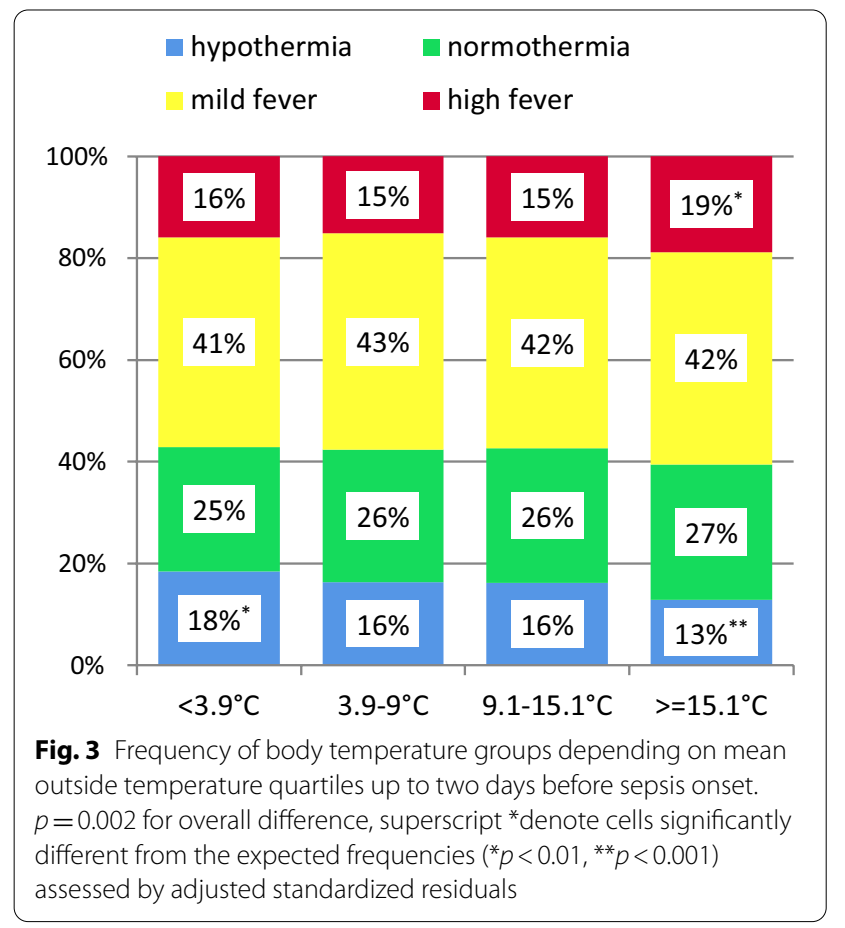

before the first blood draw in most clinical scenarios [28]. The mechanisms regulating hypothermia, which involve much of the same cytokines that regulate fever, are not well understood [10, 24-27]. In animal experiments, a thermoregulatory reaction to sepsis dependent on environmental temperature has been observed $[9,10]$. This has been interpreted as poikilothermia, meaning a dissociation of the upper and lower threshold of temperature regulation where body temperature becomes dependent on outside conditions [9]. But recent data indicate a wellregulated mechanism where activated immunity is in an energetic trade-off with homeothermy [10]. Under cold conditions or calorie restriction, mice show a hypometabolic response promoting tolerance, while warm and well-fed mice show a normothermic response promoting resistance but associated with a higher mortality [10]. In our data, a lower BMI and older age, both surrogates of lower metabolic fitness, were associated with hypothermia in line with previous findings from a smaller cohort [25]. Further factors associated with hypothermia (abdominal focus) or its absence (ICU-acquired sepsis) are difficult to interpret as abdominal surgery might promote hypothermia and ICU care is associated with multiple manipulations of active warming, administration of energy substrates and interventions aimed at the restoration of cardiopulmonary homeostasis already in the early phase of disease.

To our knowledge, we are the first to show an influence of environmental temperature on the thermoregulatory response in septic humans while a hypothermic response to a cold environment depending on metabolic reserves has been described long ago [29], and an adaptive hypometabolic state in critical illness has been theoretically discussed recently [30]. The average outside temperature for the hospital location is only a proxy for the situation of the individual patient, which is dependent on local

Table 2 Predictors of body temperature groups—multinominal logistic regression

\begin{tabular}{|c|c|c|c|c|}
\hline Variable & Hypothermia $\leq 36.5^{\circ} \mathrm{C}$ & Normothermia $35.6-37.5^{\circ} \mathrm{C}$ & Mild fever $37.6-39^{\circ} \mathrm{C}$ & High fever $\geq 39.1^{\circ} \mathrm{C}$ \\
\hline Pathogen in $B C$ & $0.96(0.80-1.17)$ & $0.79(0.67-0.93)^{* *}$ & Reference category & $1.74(1.46-2.08)^{* * *}$ \\
\hline \multicolumn{5}{|l|}{ Origin of infection } \\
\hline Community & $1.37(1.13-1.66)^{* *}$ & $1.09(0.92-1.28)$ & & $1.34(1.09-1.65)^{* *}$ \\
\hline $\mathrm{ICU}$ & $0.50(0.39-0.64)^{* * *}$ & $0.66(0.54-0.80)^{* * *}$ & & $1.44(1.15-1.82)^{* *}$ \\
\hline Ward/nursing home & Reference & Reference & & Reference \\
\hline \multicolumn{5}{|l|}{ Focus of infection } \\
\hline Respiratory & $0.72(0.56-0.92)^{*}$ & $0.77(0.62-0.95)^{*}$ & & $0.89(0.71-1.11)$ \\
\hline Abdominal & $1.32(1.04-1.68)^{*}$ & $1.38(1.12-1.69)^{* *}$ & & $0.44(0.34-0.56)^{* * *}$ \\
\hline Urogenital & $0.86(0.59-1.27)$ & $1.20(0.88-1.63)$ & & $0.95(0.69-1.31)$ \\
\hline Bones/soft tissue & $1.38(0.99-1.91)$ & $1.39(1.05-1.85)^{*}$ & & $0.76(0.54-1.08)$ \\
\hline Other/unknown & Reference & Reference & & Reference \\
\hline Age (per 10 years) & $1.11(1.04-1.18)^{* * *}$ & $1.15(1.09-1.22)^{* * *}$ & & $0.87(0.82-0.92)^{* * *}$ \\
\hline BMI (per 5 points) & $0.82(0.76-0.87)^{* * *}$ & $0.92(0.88-0.97)^{* *}$ & & $1.03(0.99-1.08)$ \\
\hline Procalcitonin log 10 & $0.96(0.85-1.08)$ & $1.01(0.92-1.12)$ & & $1.43(1.28-1.60)^{* * *}$ \\
\hline Mean temperature (per $10^{\circ} \mathrm{C}$ ) & $0.83(0.74-0.93)^{* *}$ & $1.01(0.91-1.11)$ & & $1.12(0.99-1.25)$ \\
\hline
\end{tabular}

Multinomial hierarchical logistic regression model with random intercepts for study centers for the prediction of body temperature category based on 5166 cases with all necessary data available

Leucopenia, leucocyte count and sex were not significantly associated and omitted from the final model. $p$ values were $<0.001$ for all predictors included in the model. ${ }^{*}$ Denotes predictors significantly associated $\left({ }^{*} p<0.05,{ }^{* *} p<0.01,{ }^{* * *} p<0.001\right)$ with the body temperature category 


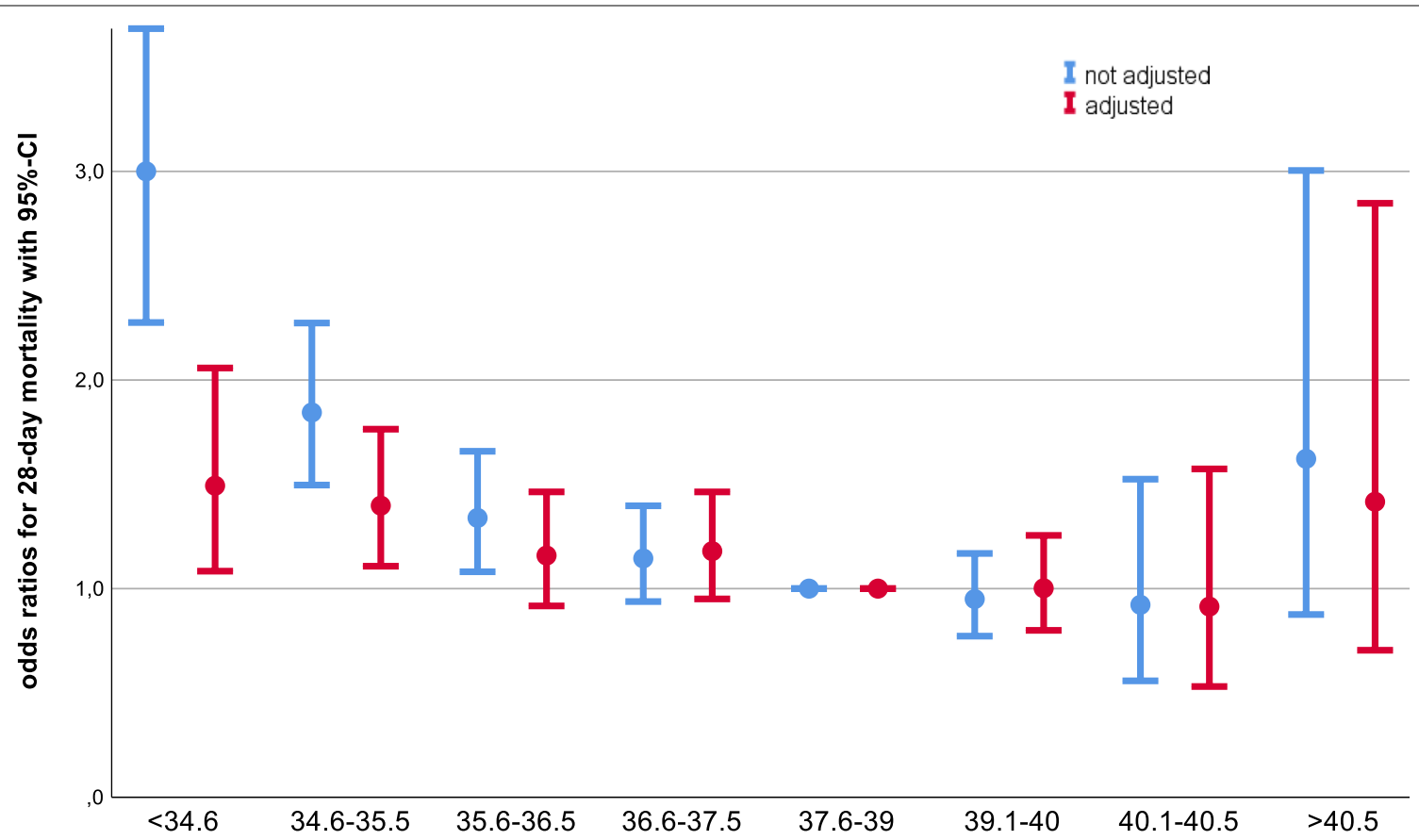

Fig. 4 Odds ratios for 28-day mortality from a logistic regression model without and with adjustment for other predictors of mortality (see Additional file 2: aT1\&aT2)

weather at the place and time of disease onset, housing, heating and clothing. In hospital-acquired sepsis, the exposure to cold conditions should be limited, and community-acquired sepsis was indeed associated with hypothermia. When it comes to warmer outside temperatures, one should keep in mind that private homes, normal hospital wards and even some ICUs in Germany are not regularly air-conditioned, resulting in a direct association of warm outside and indoor temperatures. Being able to show an effect with such an imperfect proxy might indicate that the real effect must be quite large as it is still discernible from the statistical noise.

Opposed to mice, hypothermia in human sepsis is associated with higher mortality in our data and the literature [11]. But compared to animal experiments, where only caloric intake or environmental temperature is manipulated, human patients are much more heterogeneous. Age, for example, is associated with hypothermia and worse outcome. After adjusting for factors associated with the type of thermoregulatory response and severity of illness, the association between hypothermia and mortality was much less pronounced but still present. Therefore, the hotly debated question whether and in which patients' high fever or hypothermia is an adaptive or a maladaptive and possibly detrimental response $[9,31,32]$ remains open. But the question is of utmost importance as there is a tendency to correct body temperature toward a perceived normal by physical or pharmacological means as part of routine care and in clinical trials [33-37]. For the treatment of fever, there is relatively good data that in general, patients do not benefit from temperature control $[35,37]$ even though it is widely used [38], but patients with a fever above $40{ }^{\circ} \mathrm{C}$ are barely represented in those studies. While inducing hypothermia is probably harmful [36], there are no clinical data proving that hypothermic patients profit from active warming measures aiming for normothermia or mild fever. Only a small pilot study is dealing with the question so far (NCT02706275).

Some differences in quality of care depending on body temperature are in line with previous findings $[39,40]$. Not surprisingly in the presence of fever, physicians are quicker to administer antimicrobials and to draw blood cultures, especially as they expect a higher rate of pathogen detection than in febrile patients $[41,42]$.

Our analysis has several strengths and weaknesses. To our knowledge, it is the first study on the subject using a large number of cases to look at several degrees of fever and hypothermia and to look at environmental temperature as an associated factor. As this is a secondary analysis of data from a multicenter quality improvement trial, the available information is limited. Unfortunately, we have no detailed information on oxygen delivery or consumption, no detailed medical history with potentially relevant comorbidities, no information on antipyretic medication or sedatives, no cytokine panel, no 
information on the patients' real environmental conditions and no serial temperature measurements. Therefore, we cannot use temperature trajectories to further distinguish our patient groups [43]. Temperature was also measured in an unstandardized way in different body locations. Even though to our knowledge there has been no systematic change in temperature management over the last ten years, our dataset might not be fully representative of today's patients due to changes in sepsis management. Confounding due to differences on the hospital level is of special concern when analyzing outside temperature, which is clearly associated with a hospital's location. We took clustering into account by including random intercepts into our regression analyses but could not assess the influence of specific hospital factors with forty clusters.

\section{Conclusion}

Fever and hypothermia are the two different responses in human sepsis while normothermia is rare. Even though associated with several factors including environmental conditions, their regulatory causes and their potential impact on outcome is poorly understood, more detailed observational studies are needed to understand those before the therapeutic interventions targeting body temperature or metabolic adaptation in general can be tested in the right target population.

\author{
Abbreviations \\ PCT: Procalcitonin; ICU: Intensive care unit; Cl: Confidence interval; IQR: Inter- \\ quartile range; CRP: C-reactive protein; WBC: White blood cell count; SOFA: \\ Sequential Organ Failure Assessment Score; ANOVA: Analysis of variance; BMI: \\ Body mass index.
}

\section{Supplementary Information}

The online version contains supplementary material available at https://doi. org/10.1186/s13054-021-03776-2.

Additional file 1: All involved ethical bodies with reference number of the vote.

Additional file 2: Additional tables and figures.

\section{Acknowledgements}

Some preliminary analyses were presented as an abstract at the ESICM LIVES 2017 in Vienna [44]. The following institutions and investigators participated in the collection of the used dataset: University Hospital RWTH Aachen, Department of Intensive Care Medicine: Gernot Marx, Achim Schindler, Tobias Schürholz; Ilm-Kreis-Kliniken Arnstadt, Department of Anesthesiology and Intensive Care Medicine: Heike Schlegel-Höfner, Gunther Lehmann, Annett Sander, Steffen Friese, Christian Scholz; Helios Hospital Aue, Department of Anesthesiology and Intensive Care Medicine: Pia Fischer; Zentralklinik Bad Berka GmbH, Department of Anaesthesia and Intensive Care Medicine: Christina Fuchs, Lutz Becher, Norbert Salewsky, Torsten Schreiber; Charité Berlin, Department of Anesthesiology and Operative Intensive Care Medicine: Anton Goldmann, Didier Keh, Katrin Schmid; Hufeland-Klinikum Bad Langensalza, Department of Anesthesiology and Intensive Care Medicine: Winfried
Menning, Renate Steuckart; Bundeswehrkrankenhaus Berlin, Department of Anesthesiology and Intensive Care Medicine: Robert Barz, Karin Dey, Meike Fahrenholz, Martin Müller; Vivantes Klinikum Neukölln-Berlin, Department of Anesthesiology, Surgical Intensive Care Medicine, and Pain Therapy: Herwig Gerlach, Susanne Toussaint; Helios Hospital Berlin-Buch, Department of Intensive Care Medicine: Jörg Brederlau; Ev. Hospital Bielefeld, Department of Anesthesiology, Emergency and Intensive Care Medicine, and Pain Therapy: Friedhelm Bach, Dirk Buschmann, Ingo Gummelt, J. Hoeschen, Marion Klaproth, Ina Vedder; HELIOS-Hospital St. Josefs-Hospital Bochum-Linden, Department of Anesthesiology: Ulrike Bachmann-Holdau; St. Georg Hospital Eisenach, Department of Anesthesiology and Intensive Care Medicine: Jürgen Eiche, Rolf Hauschild; Hospital Rudolf Elle, Eisenberg, Department of Anesthesiology and Intensive Care Medicine: Martina Lange, Davia HerrmannKarbaum; Helios-Hospital Emil-von Behring, Department of Interdisciplinary Intensive Care and Emergency Medicine: Annette Lubasch, Marcus Rücker; Helios-Hospital Erfurt, Department of Anesthesiology and Intensive Care Medicine: Christian Icke, Alexander Lucht, Andreas Meier-Hellmann, Jan Wagner; Catholic Hospital St. Johann Nepomuk Erfurt, Department of Anesthesiology and Intensive Care Medicine: Olaf Arnold, Steffen Kästner, Tobias Clausen; Hospital Friedberg, Department of Internal Medicine: Michael Sternkopf, Robert Voswinckel; SRH Waldklinikum Gera, Department of Anesthesiology and Intensive Care Medicine:T. Benndorf, Christel Eiserloh, Gerhard Kuhnle, Mathias Koch; University Hospital Greifswald, Department of Anesthesiology and Intensive Care Medicine: Manuela Gerber, Matthias Gründling, Liane Guderian, Sven-Olaf Kuhn, Christian Scheer; Hospital Ilmenau; Department of Anesthesiology and Intensive Care Medicine: Gerd Scheiber; Jena University Hospital, Center for Sepsis Control \& Care/Department of Anesthesiology and Intensive Care Medicine: Frank Bloos, Susann Christink, Martina Kortegast, Claudia Matthäus-Krämer, Marcel Mücke, Bernhard Poidinger, Hendrik Rüddel, Ulrike Redlich, Daniel Schwarzkopf, Daniel Thomas-Rüddel, Christel Volkmer; University Hospital Kiel, Department of Anesthesiology and Intensive Care Medicine: Stefanie D'Aria, Thees Lemke, Birgit Michaelsen, Dirk Schädler, Nina Schulz-Ruhtenberg, Norbert Weiler; Hospital Landshut-Achdorf, Department of Anesthesiology and Surgical Intensive Care Medicine: Martin Anetseder, Zoran Textor; University Hospital Leipzig, Department of Anesthesiology and Intensive Care Medicine: Udo Kaisers, Philipp Simon; Hospital Meiningen, Department of Intensive Care and Emergency Medicine: Georg Braun, Nicole Jensen, Werner Gegenfurtner, Alexander Meinhardt, Robert Schmitt, Andrea Teichert; Saale-Unstrut-Hospital Naumburg, Department of Anesthesiology and Intensive Care Medicine: Klaus-Dieter Becker; Hospital Oldenburg, Department of Anesthesiology, Intensive Care Medicine; Emergency Medicine, and Pain Therapy: Anja Diers, Florian Jelschen, Andreas Weyland; Thüringen-Klinik Pößneck, Department of Anesthesiology and Intensive Care Medicine: Frieder Knebel, Thomas Kupfer; Asklepios Hospital Radeberg, Department of Intensive Care and Emergency Medicine: Rüdinger Sinz; Thüringen-Kliniken Saalfeld, Department of Anesthesiology, Intensive Care Medicine, and Pain Therapy: Petra Bautz, Annemarie Fischer; Ev. Jung-Stilling Hospital Siegen, Department of Anesthesiology, Intensive Care, and Emergency Medicine: Armin Seibel, Christoph Fleischhacker; University Hospital Tübingen; Department of Anesthesiology: Helene Häberle, Philipp Henn, Friederike Mezger, Peter Rosenberger; University Hospital Tübingen; Dept of Internal Medicine: Reimer Riessen, Silvia Ziegler; University Hospital Medical School Ulm, Clinic of Anaesthesiology: Eberhard Barth, Hendrik Bracht, I. Heymann, A. Hinder, R. Sens, Manfred Weiss; Hufeland Hospital Weimar; Department of Anesthesiology and Intensive Care Medicine: Christof Lascho, Henriette Micke, Falk Schmidt; Helios Hospital Wuppertal. Department of Intensive Care Medicine: Stefanie Schilling, Gabriele Wöbker.

\section{Authors' contributions}

DTR planned the secondary analysis presented in the manuscript and conducted most of the statistical analysis. DS did additional analysis and graphics. PH calculated and provided the weather data matched to the cases, and MK helped with their analysis. All authors participated in the interpretation of results. DTR drafted the manuscript and all authors revised it critically for important intellectual content. KR and FBL designed, organized and led the cluster randomized trial whose dataset was analyzed. DTR, CS, FB, DS, HG, $\mathrm{MW}, \mathrm{MK}, \mathrm{HR}, \mathrm{PS}, \mathrm{SK}$, and FBL participated in the original data collection. All authors gave final consent of the version to be published. All authors read and approved the final manuscript. 


\section{Funding}

Open Access funding enabled and organized by Projekt DEAL. The original trial (NCT01187134) whose dataset was analyzed was funded by the German Federal Ministry of Education and Research via the integrated research and treatment center "Center for Sepsis Control and Care" (FKZ 01EO1002). The funding body had no part in the design, analysis and interpretation of data in the presented manuscript.

\section{Availability of data and materials}

The datasets analyzed during the current study are available from the corresponding author on reasonable request.

\section{Declarations}

\section{Ethics approval and consent to participate}

The original trial whose dataset was analyzed was approved by the local ethics committees at each participating institution and by the responsible state data protection boards. The need for informed consent was waived by all committees and data protection boards. The main vote was by the ethics committee of the University Hospital Jena (2910-08/10). A list of all involved ethical bodies is supplied as Additional File 1. No ethics approval was necessary for this secondary analysis.

\section{Consent for publication}

\section{Not applicable.}

\section{Competing interests}

The authors declare that they have no competing interests.

\section{Author details}

${ }^{1}$ Center for Sepsis Control and Care, Jena University Hospital, Jena, Germany. ${ }^{2}$ Department of Anesthesiology and Intensive Care Medicine, Jena University Hospital, Am Klinikum 1, 07747 Jena, Germany. ${ }^{3}$ Potsdam Institute for Climate Impact Research, Potsdam, Germany. ${ }^{4}$ Department of Anesthesiology and Intensive Care Medicine, Greifswald University Hospital, Greifswald, Germany. ${ }^{5}$ Department of Anesthesiology and Intensive Care Medicine, Evangelisches Klinikum Bethel, Bielefeld, Germany. ${ }^{6}$ Department of Anesthesiology and Intensive Care Medicine, Vivantes Klinikum Neuköln, Berlin, Germany. ${ }^{7}$ Department of Anesthesiology and Intensive Care Medicine, Ulm University Hospital, Ulm, Germany. ${ }^{8}$ Department of Anesthesiology and Intensive Care Medicine, University Hospital Schleswig-Holstein, Kiel, Germany. ${ }^{9}$ Department of Anesthesiology and Intensive Care Medicine, Leipzig University Hospital, Leipzig, Germany. ${ }^{10}$ Department of Anesthesiology and Operative Intensive Care Medicine (CCM, CVK), Charité University Medical Center Berlin, Berlin, Germany.

\section{Received: 8 August 2021 Accepted: 29 September 2021}

Published online: 21 October 2021

\section{References}

1. Osler W. The study of the fevers of the south. J Am Med Assoc 1896;XXVI(21):999-1004.

2. Walter EJ, Hanna-Jumma S, Carraretto M, Forni L. The pathophysiological basis and consequences of fever. Crit Care. 2016;20(1):200.

3. Clemmer TP, Fisher CJ Jr, Bone RC, Slotman GJ, Metz CA, Thomas FO. Hypothermia in the sepsis syndrome and clinical outcome. The Methylprednisolone Severe Sepsis Study Group. Critical Care Med. 1992;20(10):1395-401

4. DuPont HL, SpinkWW. Infections due to gram-negative organisms: an analysis of 860 patients with bacteremia at the University of Minnesota Medical Center, 1958-1966. Medicine (Baltimore). 1969;48(4):307-32.

5. Mchenry MC, Martin WJ, Wellman WE. Bacteremia due to gram-negative Bacilli - review of 113 cases encountered in 5-year period 1955 through 1959. Ann Intern Med. 1962;56(2):207.

6. Bone RC, Balk RA, Cerra FB, Dellinger RP, Fein AM, Knaus WA, Schein RM, Sibbald WJ. Definitions for sepsis and organ failure and guidelines for the use of innovative therapies in sepsis. The ACCP/SCCM Consensus
Conference Committee American College of Chest Physicians/Society of Critical Care Medicine. Chest. 1992;101(6):1644-55.

7. Webb WR, Deguzman VC, Grogan JB, Artz CP. Hypothermia: its effects upon hematologic clearance in experimentally induced staphylococcal bacteremia. Surgery. 1962;52:643-7.

8. Atwood RP, Kass EH. Relationship of Body Temperature to the Lethal Action of Bacterial Endotoxin. J Clin Invest. 1964:43:151-69.

9. Romanovsky AA, Szekely M. Fever and hypothermia: two adaptive thermoregulatory responses to systemic inflammation. Med Hypotheses. 1998;50(3):219-26.

10. Ganeshan K, Nikkanen J, Man K, Leong YA, Sogawa Y, Maschek JA, Van Ry T, Chagwedera DN, Cox JE, Chawla A. Energetic trade-offs and hypometabolic states promote disease tolerance. Cell. 2019;177(2):399-413 e312.

11. Rumbus Z, Matics R, Hegyi P, Zsiboras C, Szabo I, Illes A, Petervari E, Balasko M, Marta K, Miko A, et al. Fever Is associated with reduced, hypothermia with increased mortality in septic patients: a meta-analysis of clinical trials. PLoS ONE. 2017;12(1):e0170152.

12. McCarville JL, Ayres JS. Disease tolerance: concept and mechanisms. Curr Opin Immunol. 2018;50:88-93.

13. Schneider DS, Ayres JS. Two ways to survive infection: what resistance and tolerance can teach us about treating infectious diseases. Nat Rev Immunol. 2008;8(11):889-95.

14. Steiner AA, Romanovsky AA. Energy trade-offs in host defense: immunology meets physiology. Trends Endocrinol Metab. 2019;30(12):875-8.

15. Wang A, Medzhitov R. Counting calories: the cost of inflammation. Cell. 2019;177(2):223-4.

16. Bloos F, Ruddel H, Thomas-Ruddel D, Schwarzkopf D, Pausch C, Harbarth S, Schreiber T, Grundling M, Marshall J, Simon P, et al. Effect of a multifaceted educational intervention for anti-infectious measures on sepsis mortality: a cluster randomized trial. Intensive Care Med. 2017;43(11):1602-12.

17. Bloos F, Thomas-Ruddel D, Ruddel H, Engel C, Schwarzkopf D, Marshall JC, Harbarth S, Simon P, Riessen R, Keh D, et al. Impact of compliance with infection management guidelines on outcome in patients with severe sepsis: a prospective observational multi-center study. Crit Care. 2014;18(2):R42.

18. Dokumentation des Interpolationsverfahrens [https://swift.dkrz.de/v1/ dkrz_a88e3fa5289d4987b4d3b1530c9feb13/ReKliEs-De/Supplement/ Info/Interpolationsverfahren_PIK.pdf]

19. Hoffmann P, Menz C, Spekat A. Bias adjustment for threshold-based climate indicators. Adv Sci Res. 2018;15:107-16.

20. Geneva II, Cuzzo B, Fazili T, Javaid W. Normal body temperature: a systematic review. Open Forum Infect Dis. 2019;6(4):ofz032.

21. Sauerbrei W, Royston P, Binder H. Selection of important variables and determination of functional form for continuous predictors in multivariable model building. Stat Med. 2007;26(30):5512-28.

22. Evans SS, Repasky EA, Fisher DT. Fever and the thermal regulation of immunity: the immune system feels the heat. Nat Rev Immunol. 2015;15(6):335-49.

23. Bergman A, Casadevall A. Mammalian endothermy optimally restricts fungi and metabolic costs. mBio. 2010;1(5).

24. Marik PE, Zaloga GP. Hypothermia and cytokines in septic shock. Norasept II Study Investigators. North American study of the safety and efficacy of murine monoclonal antibody to tumor necrosis factor for the treatment of septic shock. Intens Care Med. 2000;26(6):716-21.

25. Wiewel MA, Harmon MB, van Vught LA, Scicluna BP, Hoogendijk AJ, Horn J, Zwinderman AH, Cremer OL, Bonten MJ, Schultz MJ, et al. Risk factors, host response and outcome of hypothermic sepsis. Crit Care. 2016;20(1):328.

26. Bhavani SV, Wolfe KS, Hrusch CL, Greenberg JA, Krishack PA, Lin J, Lecompte-Osorio P, Carey KA, Kress JP, Coopersmith CM, et al. Temperature trajectory subphenotypes correlate with immune responses in patients with sepsis. Crit Care Med. 2020;48(11):1645-53.

27. Leon LR. Hypothermia in systemic inflammation: role of cytokines. Front Biosci. 2004;9:1877-88.

28. Meisner M. Procalcitonin: Erfahrungen mit einer neuen Meßgröße für bakterielle Infektionen und systemische Inflammation. LaboratoriumsMedizin J Lab Med. 1999;23:63.

29. Bittel J. The different types of general cold adaptation in man. Int J Sports Med. 1992;13(Suppl 1):S172-176.

30. Stanzani G, Tidswell R, Singer M. Do critical care patients hibernate? Theoretical support for less is more. Intensive Care Med. 2020;46(3):495-7. 
31. Steiner AA, Fonseca MT, Soriano FG. Should we assume that hypothermia is a dysfunction in sepsis? Crit Care (London, England). 2017;21(1):8.

32. Cunha BA. With sepsis: If fever is good, then hypothermia is bad! Critical Care Med. 2012;40(10):2926.

33. Doyle JF, Schortgen F: Should we treat pyrexia? And how do we do it? Critical care. 2016;20.

34. Drewry AM, Ablordeppey EA, Murray ET, Stoll CRT, Izadi SR, Dalton CM, Hardi AC, Fowler SA, Fuller BM, Colditz GA. Antipyretic therapy in critically ill septic patients: a systematic review and meta-analysis. Crit Care Med. 2017:45(5):806-13.

35. Dallimore J, Ebmeier S, Thayabaran D, Bellomo R, Bernard G, Schortgen F, Saxena M, Beasley R, Weatherall M, Young P. Effect of active temperature management on mortality in intensive care unit patients. Crit Care Resusc. 2018;20(2):150-63.

36. Itenov TS, Johansen ME, Bestle M, Thormar K, Hein L, Gyldensted L, Lindhardt A, Christensen H, Estrup S, Pedersen HP, et al. Induced hypothermia in patients with septic shock and respiratory failure (CASS): a randomised, controlled, open-label trial. Lancet Respir Med. 2018;6(3):183-92.

37. Young PJ, Bellomo R, Bernard GR, Niven DJ, Schortgen F, Saxena M, Beasley R, Weatherall M. Fever control in critically ill adults. An individual patient data meta-analysis of randomised controlled trials. Intens Care Med. 2019;

38. Beverly A, Walter E, Carraretto M. Management of hyperthermia and hypothermia in sepsis: a recent survey of current practice across UK intensive care units. J Intensive Care Soc. 2016;17(1):88-9.

39. Sunden-Cullberg J, Rylance R, Svefors J, Norrby-Teglund A, Bjork J, Inghammar M. Fever in the emergency department predicts survival of patients with severe sepsis and septic shock admitted to the ICU. Crit Care Med. 2017;45(4):591-9.

40. Kushimoto S, Abe T, Ogura H, Shiraishi A, Saitoh D, Fujishima S, Mayumi T, Hifumi T, Shiino Y, Nakada T-A et al. Impact of body temperature abnormalities on the implementation of sepsis bundles and outcomes in patients with severe sepsis: a retrospective sub-analysis of the focused outcome research on emergency care for acute respiratory distress syndrome, sepsis and trauma study. Crit Care Med; 2019.

41. Linsenmeyer K, Gupta K, Strymish JM, Dhanani M, Brecher SM, Breu AC. Culture if spikes? Indications and yield of blood cultures in hospitalized medical patients. J Hosp Med. 2016;11(5):336-40.

42. Taniguchi T, Tsuha S, Shiiki S, Narita M. High positivity of blood cultures obtained within two hours after shaking chills. Int J Infect Dis. 2018;76:23-8.

43. Bhavani SV, Carey KA, Gilbert ER, Afshar M, Verhoef PA, Churpek MM. Identifying novel sepsis subphenotypes using temperature trajectories. Am J Respirat Crit Care Med. 2019;

44. ESICM LIVES 2017: 30th ESICM annual congress. September 23-27, 2017. Intensive Care Med Exp. 2017;5(Suppl 2):44.

\section{Publisher's Note}

Springer Nature remains neutral with regard to jurisdictional claims in published maps and institutional affiliations.
Ready to submit your research? Choose BMC and benefit from:

- fast, convenient online submission

- thorough peer review by experienced researchers in your field

- rapid publication on acceptance

- support for research data, including large and complex data types

- gold Open Access which fosters wider collaboration and increased citations

- maximum visibility for your research: over 100M website views per year

At BMC, research is always in progress.

Learn more biomedcentral.com/submissions 